\title{
Potential risk factors for the development of seroma following mastectomy with axillary dissection
}

\author{
XIAO-FENG PAN, JIN-LIANG HUAN and XIAN-JU QIN \\ Department of General Surgery, Shanghai Eighth People's Hospital, Shanghai 200235, P.R. China
}

Received January 3, 2014; Accepted August 27, 2014

DOI: $10.3892 / \mathrm{mco} .2014 .430$

\begin{abstract}
Seroma is a common complication following breast cancer surgery and the controllable predictive factors remain unknown. Patients who underwent mastectomy with axillary dissection between 2008 and 2011 in our hospital were retrospectively investigated. The demographics, clinical characteristics and therapeutic factors of each patient were recorded. The association of seroma incidence with each variable was evaluated by univariate logistic regression analysis. All the variables were considered independent predictors of seroma incidence. The probability of developing seroma following surgery was evaluated by multivariate logistic regression analysis. A total of 102 patients, with a mean age of $54.86 \pm 13.02$ years (range, 30-89 years), were included in this study and the incidence of seroma was found to be $22.55 \%$. The operative time $(\mathrm{P}=0.0066$, coefficient $=0.0261, \mathrm{OR}=1.03)$ and the use of patient-controlled intravenous analgesia (PCA) $(\mathrm{P}=0.0002$, coefficient $=-1.8089, \mathrm{OR}=0.03$, ref $=$ no $)$ was significantly associated with the incidence of seroma postoperatively. In conclusion, the prediction of the development of seroma following mastectomy with axillary dissection is challenging. However, a longer operative time and the non-use of PCA may represent potential risk factors for this complication.
\end{abstract}

\section{Introduction}

Seroma formation has been troubling patients and surgeons for over a century, since the first mastectomy was performed by Halsted in 1882. Seroma is defined as a subcutaneous collection of serous fluid post-mastectomy under the skin flap, in the dead space of the axilla or the breast following breast-conserving surgery. Seroma is a common complication following breast cancer surgery and several surgeons consider it an 'unavoidable nuisance' $(1,2)$. Seroma may prolong patient recovery and hospital stay, increase health care costs and

Correspondence to: Dr Xian-Ju Qin, Department of General Surgery, Shanghai Eighth People's Hospital, 8 Caobao Road, Shanghai 200235, P.R. China

E-mail: qinxj@hotmail.com

Key words: breast cancer, mastectomy, axillary dissection, seroma, complication possibly delay the administration of systemic treatment where required (3). The controllable predictive factors for seroma formation remain unknown. In this study, we aimed to identify the factors that may predict the formation of seroma in patients who underwent mastectomy with axillary dissection (AD) in our hospital.

\section{Patients and methods}

Patients. A total of 102 patients (101 women and 1 man), with a mean age of 54.86 \pm 13.02 years (range, 30-89 years) diagnosed with invasive ductal carcinoma by core needle biopsy or incisional biopsy, who underwent mastectomy with AD due to local recurrence following lumpectomy between 2008 and 2011 in our hospital were considered as eligible for inclusion in this study. Patients who received neoadjuvant chemotherapy or breast reconstruction immediately following mastectomy were excluded.

This study was approved by the Institutional Review Board of Shanghai Eighth People's Hospital, Shanghai, China. As the data analyzed in this study were obtained anonymously, written consent from eligible patients was not required; however, written informed consent was obtained from each patient prior to surgery for their information to be stored in our hospital databases and used for research.

Procedures. We performed mastectomy with AD according to the guidelines of the National Comprehensive Cancer Network and the decisions of the patients (some of the patients who fulfilled the criteria for breast-conserving surgery and/or sentinel limph node biopsy decided to undergo mastectomy with AD. At the end of the surgical procedure, two closed suction catheters were placed in the wound (one in the axilla and one in the chest wall). Pressure garments were used in all the patients following surgery. The drainages were removed when the drainage volume decreased to $<30 \mathrm{ml}$ per day for 3 consecutive days. All the patients were reviewed within 1 week following discharge from the hospital, unless seroma formation was detected prior to discharge. The patients who developed seroma following surgery were diagnosed by physical examination and treated by aspiration under sterile conditions. The demographic data (age, menopausal status, body weight and body height), clinical characteristics (preoperative serum albumin level, hemoglobin concentration, tumor diameter, axillary lymph node status, history of hypertension 
Table I. Univariate logistic regression analysis of characteristics potentially associated with postoperative seroma formation.

\begin{tabular}{|c|c|c|c|c|c|}
\hline Characteristics & Mean \pm SD & $\begin{array}{l}\text { Patient no. }(\%) \\
\qquad(\mathrm{n}=102)\end{array}$ & $\begin{array}{c}\text { Cases with } \\
\text { seroma, no. }(\%) \\
(n=23)\end{array}$ & OR $(95 \% \mathrm{CI})$ & P-value \\
\hline \multicolumn{6}{|l|}{ Demographics } \\
\hline Age (years) & $54.86 \pm 13.02$ & - & - & $1.00(0.96-1.04)$ & 0.9731 \\
\hline \multicolumn{6}{|l|}{ Menstrual status $(n=101)^{b}$} \\
\hline Postmenopausal & - & $57(56.44)$ & $12(21.05)$ & $1.25(0.49-3.18)$ & 0.6394 \\
\hline Premenopausal & - & $44(43.56)$ & $11(25.00)$ & - & - \\
\hline Body weight (kg) & $58.45 \pm 8.11$ & - & - & $1.00(0.95-1.06)$ & 0.8919 \\
\hline Body height (cm) & $159.33 \pm 4.39$ & - & - & $0.92(0.82-1.02)$ & 0.1242 \\
\hline \multicolumn{6}{|l|}{ Clinical characteristics } \\
\hline Serum albumin $(\mathrm{g} / \mathrm{l})$ & $70.37 \pm 5.44$ & - & - & $0.95(0.87-1.04)$ & 0.2855 \\
\hline Hemoglobin (g/l) & $128.17 \pm 11.90$ & - & - & $0.97(0.93-1.01)$ & 0.1606 \\
\hline \multicolumn{6}{|l|}{ Tumor diameter (cm) } \\
\hline$<2$ & - & $47(46.08)$ & $10(21.28)$ & $2.70(0.31-23.68)$ & 0.6116 \\
\hline $2-5$ & - & $44(43.14)$ & $12(27.27)$ & 3.75 & 0.2040 \\
\hline$>5$ & - & $11(10.78)$ & $1(9.09)$ & - & - \\
\hline \multicolumn{6}{|l|}{ Axillary lymph node status } \\
\hline Positive & - & $34(33.33)$ & $5(14.71)$ & $2.09(0.70-6.22)$ & 0.1861 \\
\hline Negative & - & $68(66.67)$ & $18(26.47$ & - & - \\
\hline \multicolumn{6}{|l|}{ Hypertension } \\
\hline Yes & - & $15(14.71)$ & $6(40.00)$ & $0.36(0.114-1.163)$ & 0.0882 \\
\hline No & - & $87(85.29)$ & $17(19.54)$ & - & - \\
\hline \multicolumn{6}{|l|}{ Diabetes mellitus } \\
\hline Yes & - & $4(3.92)$ & $1(25.00)$ & $0.87(0.09-8.77)$ & 0.9048 \\
\hline No & & $98(96.08)$ & $22(22.45)$ & - & - \\
\hline \multicolumn{6}{|l|}{ Therapeutic factors } \\
\hline Operative time (min) & $128.01 \pm 43.40$ & - & - & $1.01(1.00-1.03)$ & $0.0137^{\mathrm{a}}$ \\
\hline Initial 48-h drain output (ml) & $273.85 \pm 128.30$ & - & - & $1.00(1.00-1.01)$ & 0.1150 \\
\hline Duration of drain in situ (days) & $12.12 \pm 6.36$ & - & - & $1.04(0.97-1.12)$ & 0.2217 \\
\hline \multicolumn{6}{|l|}{ Intravenous analgesia } \\
\hline Yes & - & $57(55.88)$ & $3(5.26)$ & $14.40(3.91-52.98)$ & $<.0001^{\mathrm{a}}$ \\
\hline No & - & $45(44.12)$ & $20(44.44)$ & - & - \\
\hline
\end{tabular}

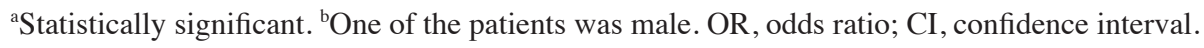

and diabetes) and therapeutic factors [operative time, volume of initial 48-h drain output, duration of drain in situ and use of patient-controlled intravenous analgesia (PCA)] of each patient were recorded and retrospectively collected.

Statistical analysis. The association of seroma incidence and each variable of the demographic, clinical characteristics and postoperative factors (operative time, volume of initial 48-h drain output, duration of drainage and use of PCA) were evaluated by univariate logistic regression analysis. All the variables were considered as independent predictors of seroma incidence. The probability of developing seroma following surgery was assessed by multivariate logistic regression analysis. All the statistical tests were performed using SAS software, version 9.1 (SAS Institute Inc., Cary, NC, USA) and the two-sided significance level was set at $\mathrm{P}<0.05$.

\section{Results}

Patients. A total of 102 patients with a mean age of $54.86 \pm 13.02$ years (range, 30-89 years) were included in this study. Of the 102 patients, 101 were female and 1 was male. The mean body weight of the patients was $58.45 \pm 8.11 \mathrm{~kg}$ (range, $43-82 \mathrm{~kg}$ ) and their mean body height was $159.33 \pm 4.39 \mathrm{~cm}$ (range, $148-171 \mathrm{~cm}$ ). A total of 23 patients (22.55\%) developed seroma postoperatively and they were all treated with aspiration.

Seroma incidence and patient characteristics. The mean preoperative serum albumin level was $70.37 \pm 5.44 \mathrm{~g} / 1$ (range, 60-86 g/l) and the mean preoperative hemoglobin concentration was $128.17 \pm 11.90 \mathrm{~g} / \mathrm{l}$ (range, 98-160 g/l). Twelve of the 57 postmenopausal and 11 of the 44 premenopausal 
Table II. Multivariate logistic regression analysis of characteristics potentially associated with postoperative seroma formation.

\begin{tabular}{|c|c|c|c|c|}
\hline Characteristics & Coefficient & Standard error & OR $(95 \% \mathrm{CI})$ & P-value \\
\hline \multicolumn{5}{|l|}{ Demographics } \\
\hline Age & 0.00 & 0.05 & $1.00(0.90-1.10)$ & 0.9277 \\
\hline \multicolumn{5}{|l|}{ Menstrual status } \\
\hline Postmenopausal & -0.07 & 0.63 & $0.87(0.08-10.15)$ & 0.9116 \\
\hline Premenopausal & - & - & - & - \\
\hline Body weight & 0.03 & 0.06 & $1.03(0.92-1.15)$ & 0.6150 \\
\hline Body height & -0.20 & 0.09 & $0.82(0.68-0.98)$ & $0.0272^{\mathrm{a}}$ \\
\hline \multicolumn{5}{|l|}{ Clinical characteristics } \\
\hline Serum albumin & -0.08 & 0.08 & $0.92(0.79-1.07)$ & 0.2951 \\
\hline Hemoglobin & 0.00 & 0.04 & $1.00(0.92-1.07)$ & 0.9054 \\
\hline \multicolumn{5}{|l|}{ Tumor diameter } \\
\hline$<2 \mathrm{~cm}$ & -0.10 & 0.80 & $1.91(0.08-46.56)$ & 0.3700 \\
\hline $2-5 \mathrm{~cm}$ & 0.84 & 0.59 & $4.86(0.35-67.87)$ & - \\
\hline$>5 \mathrm{~cm}$ & - & - & - & - \\
\hline \multicolumn{5}{|l|}{ Axillary lymph node status } \\
\hline Positive & 0.11 & 0.51 & $0.80(0.11-5.86)$ & 0.8260 \\
\hline Negative & - & - & - & - \\
\hline \multicolumn{5}{|l|}{ Hypertension } \\
\hline Yes & 0.34 & 0.61 & $1.99(0.18-22.12)$ & 0.5747 \\
\hline No & - & - & - & - \\
\hline \multicolumn{5}{|l|}{ Diabetes mellitus } \\
\hline Yes & 0.63 & 0.96 & $3.53(0.08-149.35)$ & 0.5095 \\
\hline No & - & - & - & - \\
\hline \multicolumn{5}{|l|}{ Therapeutic factors } \\
\hline Operative time & 0.03 & 0.01 & $1.03(1.01-1.05)$ & $0.0066^{\mathrm{a}}$ \\
\hline Initial 48 h-drain output & 0.00 & 0.00 & $1.01(1.00-1.01)$ & 0.1630 \\
\hline Duration of drain in situ & 0.06 & 0.07 & $1.06(0.93-1.20)$ & 0.3948 \\
\hline \multicolumn{5}{|l|}{ Intravenous analgesia } \\
\hline Yes & -1.81 & 0.49 & $0.03(0.00-0.18)$ & $0.0002^{\mathrm{a}}$ \\
\hline No & - & - & - & - \\
\hline
\end{tabular}

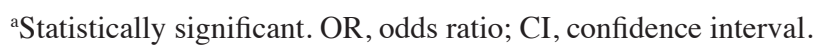

female patients developed seroma. Seromas were detected in 6 of the 15 patients with hypertension and in 17 of the 87 patients without hypertension. Of the 4 patients with diabetes mellitus, 1 developed seroma. Seromas were diagnosed in 10 of 47, 12 of 44 and 1 of 11 patients with a tumor diameter of $<2 \mathrm{~cm}, 2-5 \mathrm{~cm}$ and $>5 \mathrm{~cm}$, respectively. Of the 34 patients with positive axillary lymph nodes, 5 developed seroma.

The mean operative time was $128.01 \pm 43.40 \mathrm{~min}$ (range, 45-240 $\mathrm{min}$ ) and the mean drain output volume during the initial $48 \mathrm{~h}$ postoperatively was $273.85 \pm 128.30 \mathrm{ml}$ (range, 49-705 $\mathrm{ml}$ ). The mean duration of drainage was 12.12 \pm 6.36 days (range, $3-40$ days). Of the 57 patients receiving PCA and the 45 patients without PCA, 3 and 20 developed seroma, respectively.

The multivariate logistic regression analysis indicated that operative time was significantly associated with the incidence of seroma postoperatively $(\mathrm{P}=0.0066$, coefficient $=0.03$, $\mathrm{OR}=1.03$ ), with an increase in operative time by $10 \mathrm{~min}$ being associated with a $30 \%$ higher risk of seroma formation. The use of PCA was a significant protective factor against seroma formation $(\mathrm{P}=0.0002$, coefficient $=-1.81, \mathrm{OR}=0.03$, ref $=$ no). The odds of seroma formation among intravenous analgesia users were $97 \%$ lower compared to among non-users and PCA significantly lowered the incidence of seroma.

The factors affecting seroma formation according to the univariate and multivariate logistic regression analyses are presented in Tables I and II, respectively.

\section{Discussion}

Seroma is one of the most common complications following breast cancer surgery. The precise etiology of seroma formation remains unknown and it may delay the initiation of 
adjuvant chemotherapy and radiotherapy, predispose to wound infection, delay wound healing and may also be associated with arm lymphoedema $(2,4-7)$, which may be the cause of unnecessary tribulation and worse patient outcome. Although seroma is considered to consist of lymphatic fluid due to lymphatic vessel damage, its pathophysiology remains poorly understood and controversial $(3,5,7)$. The reported incidence of seroma varies widely between 8 and $81 \%(8-13)$. In our study, we observed a seroma incidence of $22.55 \%$ following modified radical mastectomy.

Several studies were focused on patient characteristics associated with the development of seroma following breast surgery. Burak et al (14) reported a positive association between body weight and seroma formation, whereas Kumar et al (15) demonstrated that hypertension was associated with an increase in the incidence of seroma. By contrast, other studies consistently reported no association between the presence of anemia (16) or diabetes mellitus (16) and seroma formation, whereas existing evidence were inconclusive regarding age (13-15,17). In our study, no patient characteristic was found to be associated with postoperative seroma formation.

As regards tumor characteristics, the data on the association between axillary lymph node status, tumor size and seroma formation were inconclusive $(13,15,17-22)$. No such association was identified by the present study.

In addition, the available evidence have been inconclusive regarding the association of the surgeon's skill or experience with seroma formation (23-25). Previous studies demonstrated that a longer operative time increases the risk of seroma formation $(16,24)$, which was consistent with our observations.

Burak et al (14) and Kopelman et al (26) reported a positive association between drain output volume during the initial $72 \mathrm{~h}$ and seroma formation. However, in our study, there was no significant association between drain output volume or duration of drain in situ and seroma formation.

Various approaches have been used to prevent seroma formation, including closing the dead space under the mastectomy skin flap by suturing (27), delaying shoulder exercises during the recovery phase (4), using external compression dressings (28), ultrasound cutting devices (29), or suction drainage systems (30), applying bovine thrombin during surgery (15), tetracycline sclerotherapy (31,32), talc poudrage (33) and using fibrin sealant (34). In our institution, certain patients requested PCA for the first $24 \mathrm{~h}$ following surgery, even if not suggested by the anaesthesiologist. In our study, we observed that the use of PCA may significantly reduce the incidence of seroma formation following mastectomy with $\mathrm{AD}$. However, this finding requires confirmation by further cohort studies and the underlying mechanism has not yet been elucidated.

In conclusion, the prediction of seroma formation following mastectomy with AD remains challenging. We identified no potential risk factors other than the longer operative time and the non-use of PCA, which are both controllable factors. In addition, the latter may represent a novel approach to the prevention of seroma following breast cancer surgery.

\section{Acknowledgements}

This study was supported by a grant from the Shanghai Xuhui Science Foundation (no. xkkt201106).

\section{References}

1. Aitken DR and Minton JP: Complications associated with mastectomy. Surg Clin North Am 63: 1331-1352, 1983

2. Pogson CJ, Adwani A and Ebbs SR: Seroma following breast cancer surgery. Eur J Surg Oncol 29: 711-717, 2003.

3. Tadych K and Donegan WL: Postmastectomy seromas and wound drainage. Surg Gynecol Obstet 165: 483-487, 1987.

4. Shamley DR, Barker K, Simonite V and Beardshaw A: Delayed versus immediate exercises following surgery for breast cancer: a systematic review. Breast Cancer Res Treat 90: 263-271, 2005.

5. Kuroi K, Shimozuma K, Taguchi T, et al: Pathophysiology of seroma in breast cancer. Breast Cancer 12: 288-293, 2005.

6. Barwell J, Campbell L, Watkins RM and Teasdale C: How long should suction drains stay in after breast surgery with axillary dissection? Ann R Coll Surg Eng1 79: 435-437, 1997.

7. Gonzalez EA, Saltzstein EC, Riedner CS and Nelson BK: Seroma formation following breast cancer surgery. Breast J 9: 385-388, 2003.

8. Roses DF, Brooks AD, Harris MN, Shapiro RL and Mitnick J: Complications of level I and II axillary dissection in the treatment of carcinoma of the breast. Ann Surg 230: 194-201, 1999.

9. Woodworth PA, McBoyle MF, Helmer SD and Beamer RL: Seroma formation after breast cancer surgery: incidence and predicting factors. Am Surg 66: 444-451, 2000.

10. Classe JM, Dupre PF, Francois T, et al: Axillary padding as an alternative to closed suction drain for ambulatory axillary lymphadenectomy: a prospective cohort of 207 patients with early breast cancer. Arch Surg 137: 169-173, 2002.

11. Abe M, Iwase T, Takeuchi T, Murai $\mathrm{H}$ and Miura S: A randomized controlled trial on the prevention of seroma after partial or total mastectomy and axillary lymph node dissection. Breast Cancer 5: 67-69, 1998

12. Somers RG, Jablon LK, Kaplan MJ, Sandler GL and Rosenblatt NK: The use of closed suction drainage after lumpectomy and axillary node dissection for breast cancer: A prospective randomized trial. Ann Surg 215: 146-149, 1992.

13. Loo WT and Chow LW: Factors predicting seroma formation after mastectomy for Chinese breast cancer patients. Indian J Cancer 44: 99-103, 2007.

14. Burak WE Jr, Goodman PS, Young DC and Farrar WB: Seroma formation following axillary dissection for breast cancer: risk factors and lack of influence of bovine thrombin. J Surg Oncol 64 : 27-31, 1997

15. Kumar S, Lal B and Misra MC: Post-mastectomy seroma: a new look into the aetiology of an old problem. J R Coll Surg Edinb 40: 292-294, 1995.

16. Say CC and Donegan W: A biostatistical evaluation of complications from mastectomy. Surg Gynecol Obstet 138: 370-376, 1974.

17. Browse DJ, Goble D and Jones PA: Axillary node clearance: who wants to immobilize the shoulder? Eur J Surg Oncol 22: 569-570, 1996.

18. Medl M, Mayerhofer K, Peters-Engl C, et al: The application of fibrin glue after axillary lymphadenectomy in the surgical treatment of human breast cancer. Anticancer Res 15: 2843-2845, 1995.

19. Petrek JA, Peters MM, Nori S, et al: Axillary lymphadenectomy. A prospective, randomized trial of 13 factors influencing drainage, including early or delayed arm mobilization. Arch Surg 125: 378-382, 1990.

20. Petrek JA, Peters MM, Cirrincione C and Thaler HT: A prospective randomized trial of single versus multiple drains in the axilla after lymphadenectomy. Surg Gynecol Obstet 175: 405-409, 1992.

21. Schuijtvlot M, Sahu AK and Cawthorn SJ: A prospective audit of the use of a buttress suture to reduce seroma formation following axillary node dissection without drains. Breast 11: 94-96.

22. Lumachi F, Brandes AA, Burelli P, et al: Seroma prevention following axillary dissection in patients with breast cancer by using ultrasound scissors: a prospective clinical study. Eur J Surg Oncol 30: 526-530, 2004.

23. Uden P, Aspegren K, Balldin G, Garne JP and Larsson SA: Fibrin adhesive in radical mastectomy. Eur J Surg 159: 263-265, 1993.

24. Schultz I, Barholm M and Grondal S: Delayed shoulder exercises in reducing seroma frequency after modified radical mastectomy: a prospective randomized study. Ann Surg Oncol 4: 293-297, 1997.

25. Tejler G and Aspegren K: Complications and hospital stay after surgery for breast cancer: a prospective study of 385 patients. $\mathrm{Br}$ J Surg 72: 542-544, 1985. 
26. Kopelman D, Klemm O, Bahous H, et al: Postoperative suction drainage of the axilla: for how long? Prospective randomised trial. Eur J Surg 165: 117-120, 1999.

27. Coveney EC, O'Dwyer PJ, Geraghty JG and O'Higgins NJ: Effect of closing dead space on seroma formation after mastectomy - a prospective randomized clinical trial. Eur J Surg Oncol 19: 143-146, 1993

28. O'Hea BJ, Ho MN and Petrek JA: External compression dressing versus standard dressing after axillary lymphadenectomy. Am J Surg 177: 450-453, 1999 .

29. Galatius H, Okholm M and Hoffmann J: Mastectomy using ultrasonic dissection: Effect on seroma formation. Breast 12: 338-341, 2003.

30. Talbot ML and Magarey CJ: Reduced use of drains following axillary lymphadenectomy for breast cancer. ANZ J Surg 72: 488-490, 2002.
31. Sitzmann JV, Dufresne C and Zuidema GD: The use of sclerotherapy for treatment of postmastectomy wound seromas. Surgery 93: 345-347, 1983.

32. Rice DC, Morris SM, Sarr MG, et al: Intraoperative topical tetracycline sclerotherapy following mastectomy: a prospective, randomized trial. J Surg Oncol 73: 224-227, 2000.

33. Coons MS, Folliguet TA, Rodriguez C, et al: Prevention of seroma formation after dissection of musculocutaneous flaps. Am Surg 59: 215-218, 1993.

34. Moore MM and Freeman MG: Fibrin sealant in breast surgery. J Long Term Eff Med Implants 8: 133-142, 1998. 